\title{
Childhood acute recurrent parotitis
}

\author{
MICHAEL J. MOSKAL, D.O., FAAP
}

Des Moines, Iowa

\begin{abstract}
Acute recurrent parotitis is a unique disorder in children. It presents clinically with multiple episodes of painful parotid swelling, which often is associated with a purulent discharge from the parotid duct. The basic defect that predisposes the child to multiple exacerbations of parotitis is obscure. However, metaplastic transformation of parotid gland serous-secreting cells and intraductal epithelium to mucusproducing cells is thought to cause a sequence of pathophysiologic events that are conducive to ascending infection. The disease in children differs from the adult form and is characterized by spontaneous remission in the majority of patients near the onset of puberty. Treatment is directed at each recurrence.
\end{abstract}

Recurrent parotid swelling, which frequently is associated with fever, pain, and a purulent discharge from the parotid duct on the involved side, is a distinct but unusual disorder that primarily affects adults and is uncommon in children. ${ }^{1,2}$ Diagnosed on the basis of history, physical examination, and sialographic investigation, acute recurrent parotitis generally is confined to the parotid glands, but it also can occur in association with Sjögren-Larsson syndrome, a systemic immunologic disease. ${ }^{3}$ At present, the pathogenesis of recurrent parotitis remains unknown. ${ }^{4}$

Because this disorder often is confused with epidemic parotitis (mumps) or more serious parotid gland disease, the clinician may be led to consider unnecessary investigative or therapeutic pro- cedures. This article describes the natural history of childhood acute recurrent parotitis through an illustrative case history and a review of the current concepts regarding diagnosis and management.

\section{Report of case}

A 5-year-old white boy was first evaluated in December 1983 with a 12 -hour history of fever of $102 \mathrm{~F}$., bilateral preauricular swelling extending below the angle of the jaw, and pain accompanying motion of the mandible. Before this episode, he had been in good health except for the usual childhood illnesses. All immunizations were complete.

Physical examination revealed a well-developed child in no acute distress. His oral temperature was $102.6 \mathrm{~F}$., heart rate 104 beats per minute, respiratory rate 24 per minute, and blood pressure $104 / 54 \mathrm{~mm}$. Hg. Parotid gland swelling was noted bilaterally, with the left parotid gland showing a $3 \times 4 \mathrm{~cm}$. indurated area that was warm to touch. When the left gland was massaged, a mucopurulent exudate was expressed from the parotid duct. However, no exudate could be obtained from the right duct. The rest of the physical examination was normal.

On hospital admission, the leukocyte count was $12,500 /$ cu. mm., with a differential distribution of 76 percent polymorphonuclear leukocytes, 2 percent band forms, 14 percent lymphocytes, 7 percent monocytes, and 1 percent atypical lymphocytes. The Wintrobe erythrocyte sedimentation rate was elevated to $19 \mathrm{~mm} . / \mathrm{hr}$., and the serum amylase level was increased to 758 I.U./L. (normal, 7-91 I.U./L.). The sweat chloride value was normal. Blood cultures were negative. A culture of the exudate from the parotid duct revealed "normal" oral flora. Acute and convalescent vital titers for mumps, herpes simplex, and parainfluenza types I, II, and III failed to demonstrate a fourfold rise in antibody titers.

The patient was administered parenteral oxacillin $(100$ $\mathrm{mg} . / \mathrm{kg}$./day) and chloramphenicol $(75 \mathrm{mg} . / \mathrm{kg} /$ day $)$. Within 24 hours of admission, defervescence and reduction in parotid gland swelling occurred. On the third day he was discharged from the hospital on a 10-day course of 
oral cefaclor $(40 \mathrm{mg} . / \mathrm{kg} . /$ day). On examination 10 days after discharge, there was no evidence of residual parotid gland disease.

Approximately 1 month after the initial episode, the patient presented to the emergency room with the acute onset of fever, bilateral parotid gland swelling, and pain. Physical examination revealed tender bilateral parotid gland edema, with the left side being more involved than the right. Exudate was spontaneously flowing from an inflamed, edematous left parotid papilla. The leukocyte count at this visit was $13,900 /$ cu.mm., with a differential count of 75 percent polymorphonuclear cells, 1 percent band forms, 20 percent lymphocytes, and 4 percent monocytes. No cultures were obtained. The patient was released from the emergency room on a 10-day course of oral amoxicillin $(40 \mathrm{mg} . / \mathrm{kg}$./day). Within 48 hours, his fever, pain, and parotid swelling had resolved.

In February 1984, the patient again had an acute onset of fever, but this time there was swelling only of the right parotid gland. He complained of severe pain with minimal movement of the jaw. Physical examination of the right parotid region revealed a $3 \times 4 \mathrm{~cm}$. area of induration, erythema, and tenderness. A purulent discharge was noted from an inflamed right parotid papilla. The leukocyte count was $15,100 /$ cu.mm., with 66 percent polymorphonuclear leukocytes, 7 percent band forms, 18 percent lymphocytes, 6 percent monocytes, 2 percent atypical lymphocytes, and 1 percent metamyelocytes. The Wintrobe sedimentation rate was $14 \mathrm{~mm} . / \mathrm{hr}$. The serum amylase level was 728 I.U./L., and the sweat chloride value was normal. Blood cultures were negative, but culture of the discharge from the right parotid papilla revealed Streptococcus pneumoniae.

The patient was admitted to the hospital for observation, and after the results of the culture and sensitivity testing were known, he was started on amoxicillin $(40$ $\mathrm{mg} . / \mathrm{kg}$./day). Improvement was rapid, and he was discharged on the third hospital day. Arrangements were made to perform a sialogram when he was asymptomatic.

Bilateral parotid sialography was performed under general anesthesia in April 1984. Both glands showed evidence of chronic inflammation with bilateral punctate sialectasia. The left gland demonstrated more extensive disease (Figs. 1A, 1B, 2A, and 2B).

During the past 36 months, the child has had frequent recurrences of acute parotitis, usually bilateral, occurring at 2 -week to 4 -month intervals. Each episode responded promptly to oral broad-spectrum antibiotics. Except for these episodes of parotitis, the child has remained in good health.

\section{Discussion}

This case report represents the classic clinical presentation and course of a child with acute recurrent parotitis. The initial episode usually occurs during the first decade of life, with a mean age at the time of diagnosis of 7-9 years. ${ }^{5,6}$ In contrast to the female preponderance found in the adult form of the disorder, males predominate in most studies involving children. ${ }^{1,7-9}$
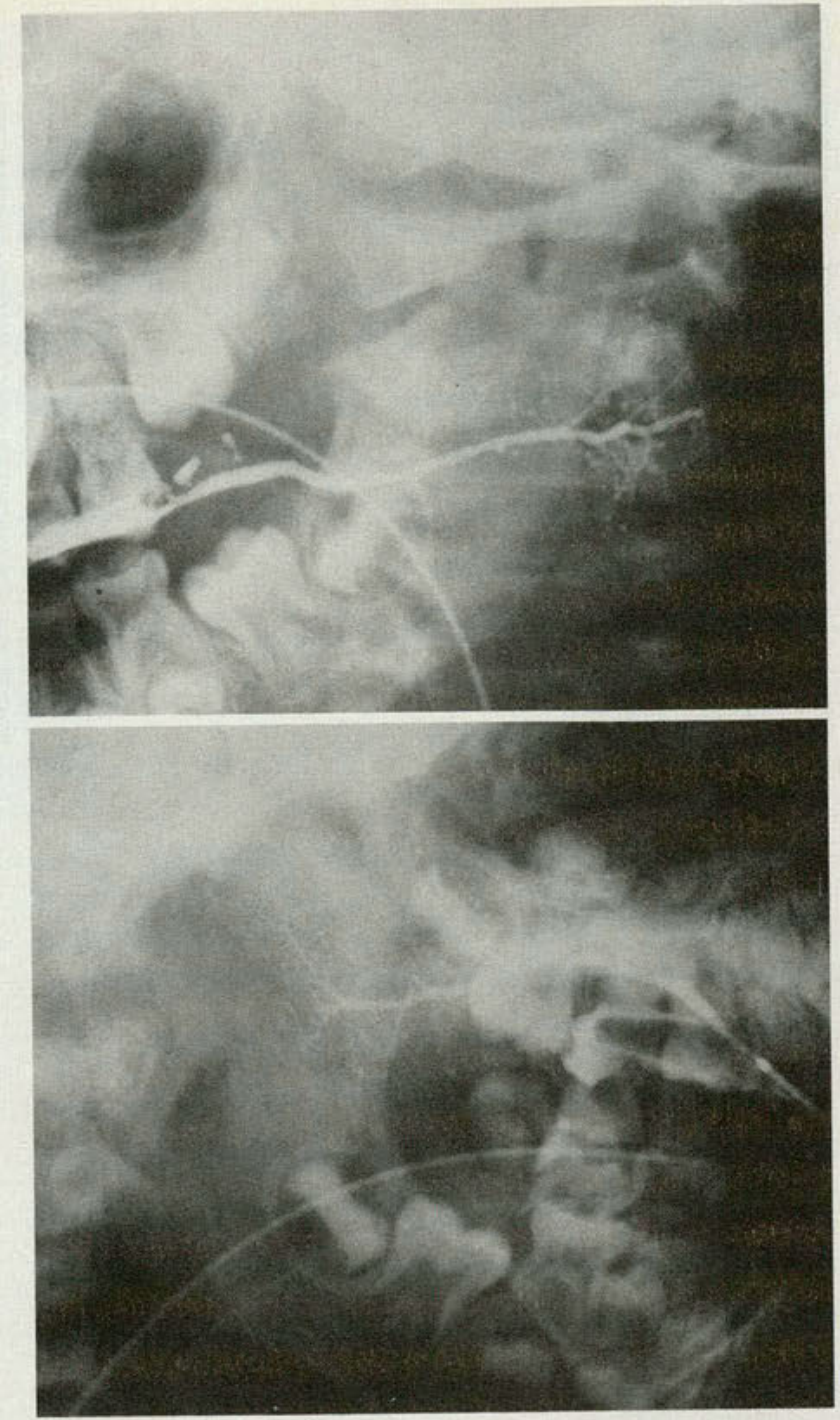

Figs. 1A and 1B. Sialographic views of left parotid area demonstrate extensive sialectasia (multiple punctate, dye-filled cavities).

Clinically, acute recurrent parotitis is characterized by frequent exacerbations of painful parotid swelling. Depending upon the individual, the time interval between attacks varies from weeks to years. ${ }^{1,6,8}$ Often, there is a history of upper respiratory tract infection in the days or weeks preceding the onset of symptoms. ${ }^{5,6}$ Parotid enlargement can develop suddenly or gradually, is most often unilateral but can be bilateral, and is generally associated with moderate discomfort. When the enlargement is unilateral, the opposite parotid gland may be involved during the next recurrence. The submandibular salivary glands usually are not affected. . $^{3,6,9}$

Physical examination reveals a swollen, tender parotid gland, which usually is less pronounced 

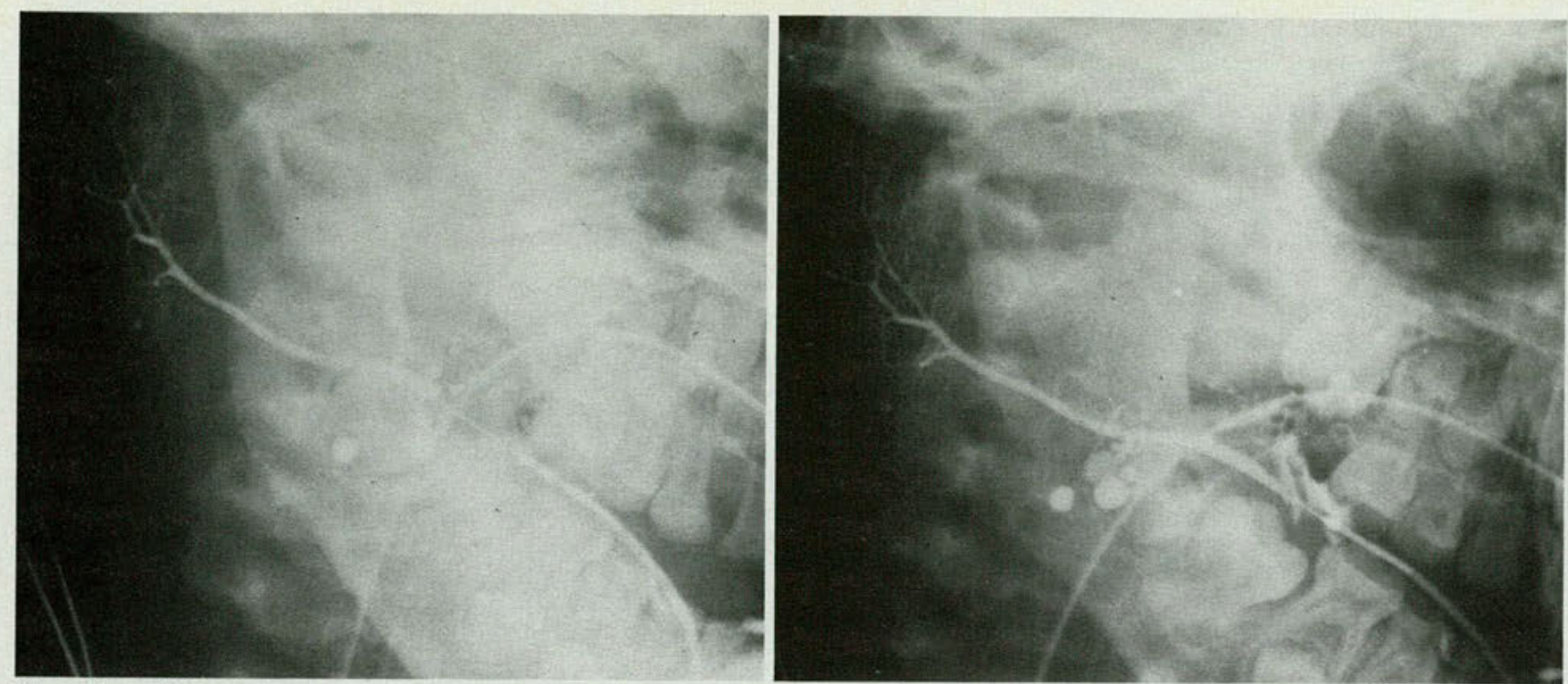

Figs. 2A and 2B. Sialographic views of right parotid area show mild sialectasia.

than that observed in mumps parotitis. ${ }^{6}$ Induration of the gland and erythema of the overlying skin occur occasionally. Intraoral examination often reveals an edematous, inflamed parotid papilla on the involved side. During the initial phase of the attack, the saliva expressed from the parotid duct generally is turbid and contains mucus and pus ("snowstorm" appearance), but it may become entirely purulent as the disease progresses. ${ }^{1,2}$ This mucopurulent exudate ordinarily is obtained after massage of the affected gland. ${ }^{1,6}$ However, as was noted in the reported case, pus can be free flowing from the duct orifice. A low-to-moderate grade fever usually accompanies these signs and symptoms. ${ }^{6,10}$

The pathogenesis of acute recurrent parotitis is poorly understood. Most authors ${ }^{1,2,8,9,11}$ believe that the key to its development is the diminished secretion and excretion of saliva secondary to the metaplastic transformation of serous secretory cells and intraductal epithelium into mucus-producing cells. This is followed by a sequence of pathophysiologic events leading to stagnation, increased intraductal pressure, and subsequent ascending bacterial infection from organisms common to the oral cavity. A proposed scheme of pathophysiologic events in recurrent parotitis is presented in Figure 3.

Why serous-producing cells and intraductal epithelium are transformed into mucus-producing cells remains a mystery. A widely accepted hypothesis attributes the basic defect to a localized abnormal immune response. . $^{1,2,4,6,10}$ In this instance, an antigen unique to the epithelium of the intralobar ducts and serous-secreting cells of the parotid gland would be recognized as foreign and eventually would lead to an autoimmune response. This

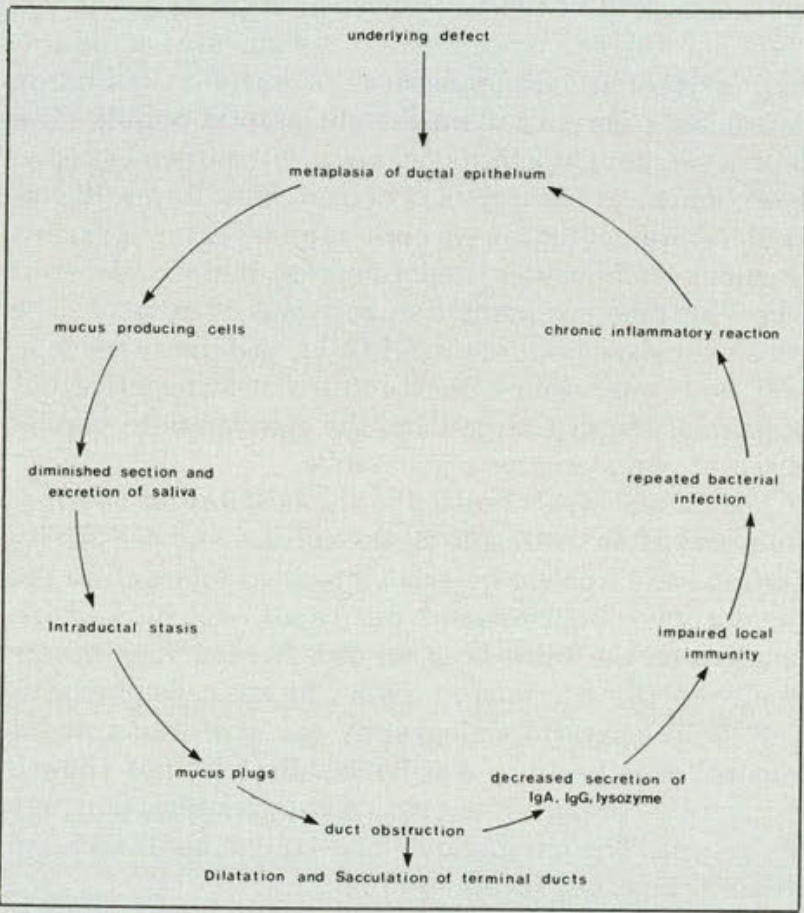

Fig. 3. Proposed scheme of pathophysiologic events in the pathogenesis of recurrent parotitis.

phenomenon, in turn, might allow a secondary infection to develop, which would prolong the inflammatory process and ultimately would lead to metaplasia of the epithelial cells. Although a few reports ${ }^{4,6,11}$ have documented autoantibodies or small-vessel immune complex deposition, no consistent data are available to support this hypothesis.

Some investigators ${ }^{3,9}$ doubt that acute recurrent parotitis is an acquired disorder and suggest that it is the result of a congenital anomaly of the parotid 
gland. This theory proposes that congenital sialectasia (terminal parotid small-duct dilatation) is the basic defect leading to secretion stagnation, infection, and metaplasia of the duct epithelium. Support for this theory arises from knowledge that sialectasia has a familial incidence and occurs in young children, and from the observation that even when the disease is unilateral, there is frequently punctate ductal dilatation of the unaffected gland. Despite the credibility of this hypothesis, there is no newborn or preterm pathologic evidence to support it. Thus, it is difficult to assert that sialectasia is the primary defect rather than a consequence of previous disease.

Other suggested causes include IgA deficiency, allergy, strictures, and anatomic aberrancy. ${ }^{2,4,12,13}$ However, there is no consistently reproducible evidence available to substantiate a causal relationship for any of these abnormalities.

Sialography is the primary diagnostic tool employed to support the diagnosis of acute recurrent parotitis. Classically, this radiographic procedure will show nonobstructive terminal small-duct sialectasia, with no evidence of stricture, calculus, or space-occupying lesions ${ }^{6,9}$ (Figs. 1A, 1B, 2A, and 2B). The large ducts are normal in appearance. If the disease is unilateral, the opposite gland still may show similar radiographic findings. Whether sialectasia is an intrinsic component of the disease or the result of extravasation of contrast material into the periductal tissue has been controversial. However, a study by Konno and Ito ${ }^{3}$ showed that the majority of the punctate shadows are cystic cavities connected to the peripheral ducts. It is noteworthy that sialectasia is not specific for childhood acute recurrent parotitis; it also has been associated with the adult onset form of the disease and SjögrenLarrson syndrome. ${ }^{3,6,9}$

The most common organisms isolated from the exudate flowing from the parotid duct are Streptococcus viridans and Diplococcus pneumoniae. These organisms are indigenous to the oral cavity and invade the parotid gland by an ascending route. The leukocyte count can be normal or elevated, with a predominance of polymorphonuclear leukocytes, and the serum amylase value can be increased.

The differential diagnosis of acute recurrent parotitis includes acute viral parotitis (including mumps), acute suppurative parotitis, calculi, catscratch disease, cystic fibrosis, neoplasm, sar-

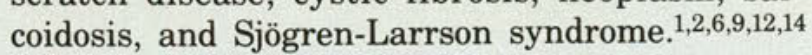
Although most of these disorders can be excluded by an adequate history and physical examination in conjunction with specific laboratory evaluation, several require further discussion, because they are frequently confused with childhood acute recurrent parotitis.

Mumps is easily diagnosed on the basis of a history of exposure to another individual with parotitis 14-21 days previously, the onset of pain, and swelling of one or both parotid glands. Pus cannot be expressed from the parotid duct. Unlike acute recurrent parotitis, submandibular salivary gland involvement occurs in 10-15 percent of patients with mumps. Mumps vaccine is $85-97$ percent effective in preventing primary mumps infection, and recurrence is rare in those who have had the naturally occurring disease. ${ }^{2,15}$ Several studies $1,2,14$ have demonstrated that parotitis can be caused by other organisms, including parainfluenza, cocksackievirus, cytomegalovirus, ECHO virus, and choriolymphocytic viruses.

Children who present with acute suppurative parotitis are toxic-appearing and frequently have a history of a debilitating underlying disease. The most common organism isolated is Staphylococcus aureus, with an occasional case revealing Hemophilus influenzae. .,2,15 $^{-15}$

The parotitis associated with Sjögren-Larrson syndrome is differentiated from acute recurrent parotitis on the basis of accompanying systemic disease. It is thought to be an autoimmune disease. Patients affected by this disorder exhibit persistent or recurrent parotid and submandibular gland swelling in conjunction with keratoconjunctivitis, xerostomia, and sicca. Concomitant rheumatoid arthritis occurs in approximately 50 percent of patients. ${ }^{9}$

Because the natural history of childhood acute recurrent parotitis is spontaneous remission at the onset of puberty, the concept of primum no nocere is important in regard to management. $1,2,3,6$ Inasmuch as the basic etiology remains unknown, treatment is directed primarily at the frequent recurrences of parotid infection and generally consists of broad-spectrum antibiotics and supportive therapy. Massage of the parotid gland in a forward direction can be helpful in the drainage of accumulated pus from the duct system and, thereby, in reducing pain. Considering the self-limiting course in children, radical treatment, such as parotidectomy, irradiation, and ligation of Stensen's duct, should be avoided. Prophylactic antibiotic therapy to prevent recurrences was ineffective in this patient.

\section{Conclusion}

Recurrent parotitis is a distinct but unusual disorder that can occur in children. Because this disease can be confused with other disorders of the parotid gland, it is important that physicians understand 
its natural history. The pathogenesis is poorly understood. In most children with recurrent parotitis, spontaneous remission occurs near puberty. Thus, therapy is primarily directed at each recurrence.

1. Brook, A.H.: Recurrent parotitis in childhood. Br Dent J 127:271-5, 16 Sep 69

2. Garvar, L.R., and Kringstein, G.J.: Recurrent parotitis in childhood. J Oral Surg 32:373-6, May 74

3. Konno, A., and Ito, E.: A study on the pathogenesis of recurrent parotitis in childhood. Ann Otol Rhinol Laryngol 88S:1-20, Nov-Dec 79

4. Friis, B., et al.: Immunological studies in two children with recurrent parotitis. Acta Paediatr Scan 72:265-8, Mar 83

5. Whinery, J.G.: The value of sialography in the diagnosis and treatment of recurring parotitis. Trans Int Conf Oral Surg 4:217-22, 1973

6. Blatt, I.M.: Chronic and recurrent inflammations about the salivary glands with special reference to children. A report of 25 cases. Laryngoscope 76:917-33, May 66

7. Wagenaar, J.: Chronic recurrent parotitis in children. Arch Chir Neerl 25:13-8, 1973

8. Shapiro, S.L.: Recurrent parotid swelling. Ear Nose Throat Mon
52:147-50, Apr 73

9 Hemenway, W.G.: Chronic punctate parotitis. Laryngoscope 81:485-509, Apr 71

10. Kaban, B.K., Mulliken, J.B., and Murray, J.E.: Sialadenitis in childhood. Am J Surg 135:570-6, Apr 78

11. Brill, S.J., and Gilfillan, R.F.: Acute parotitis associated with influenza type A. A report of 12 cases. N Engl J Med 296:1391-2, 16 Jun 77

12. Rončevič, R.: Chronic recurrent parotitis aetiopathogenesis. J Maxillofac Surg 7:234-42, Aug 79

13. Quinn, J.H., and Graham, R.: Recurrent suppurative parotitis treated by intraductal antibiotics. J Oral Surg 31:36-9, Jan 73

14. Meurman, O., et al.: Viral etiology of parotitis. Scand J Infect Dis 15:145-8, 1983

15. Brunell, P.A., et al.: Parotitis in children who had previously received mumps vaccine. Pediatrics 50:441-4, Sep 72

Accepted for publication in July 1986. Updating, as necessary, has been done by the author.

Dr. Moskal is director of the Department of Pediatrics, Des Moines General Hospital Clinics, Des Moines, Iowa

Dr. Moskal, 717 Lyon Street, Des Moines, Iowa 50309. 


\section{For seasonal allergic rhinitis}

\section{The ideal profile for \\ fast on-the-job relief}

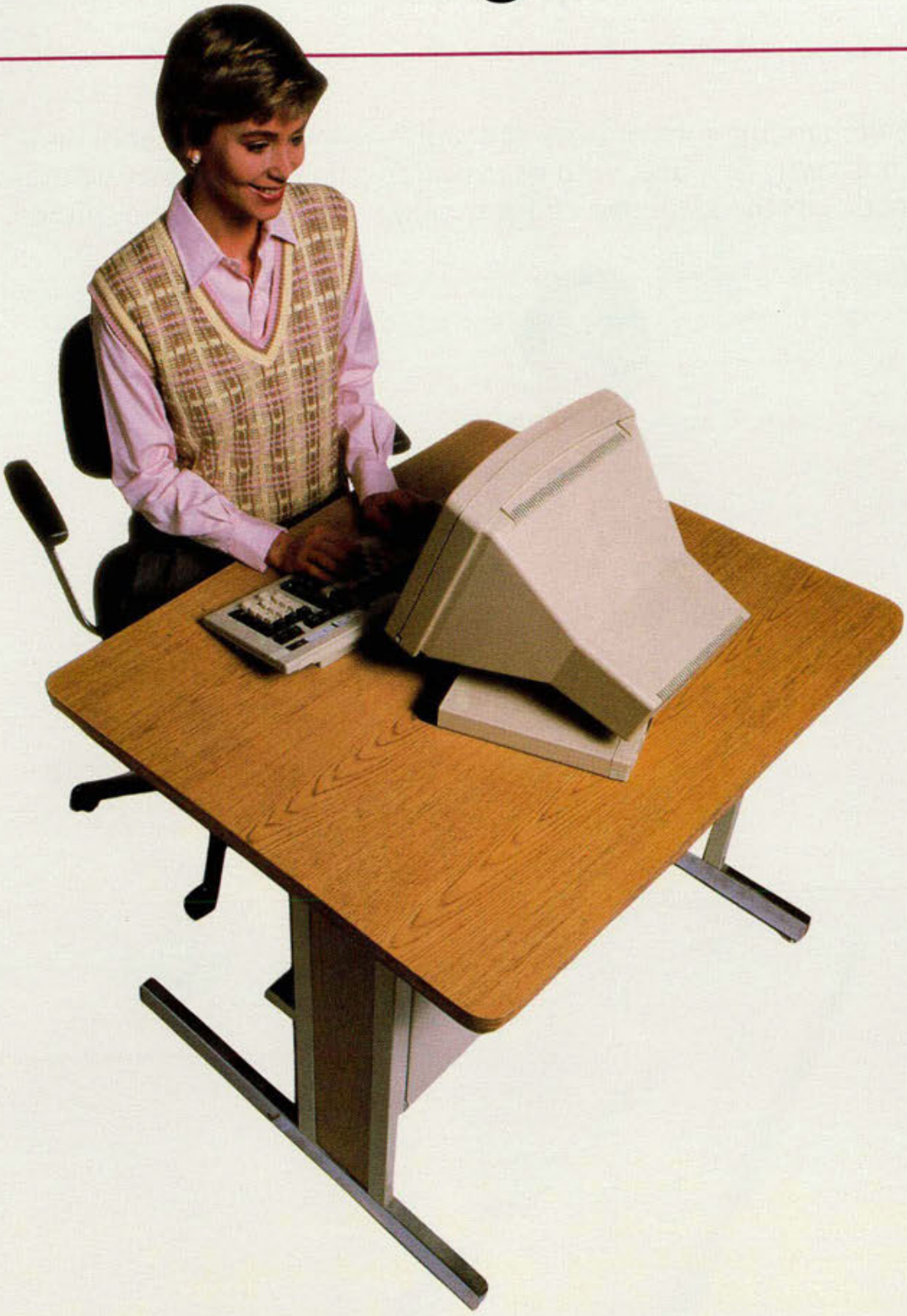

Pharmacologically distinct

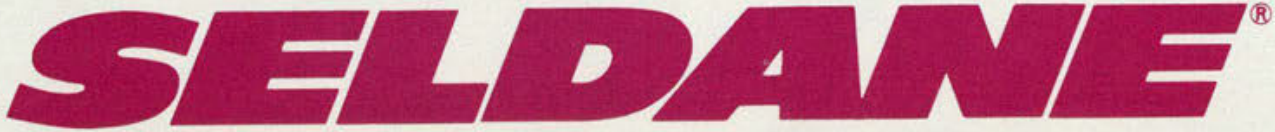

(terfenadine) $60 \mathrm{mg}$ tablets BID

The \#1 prescribed allergy product in the U.S. for seasonal allergic rhinitis 
Pharmacologically distinct
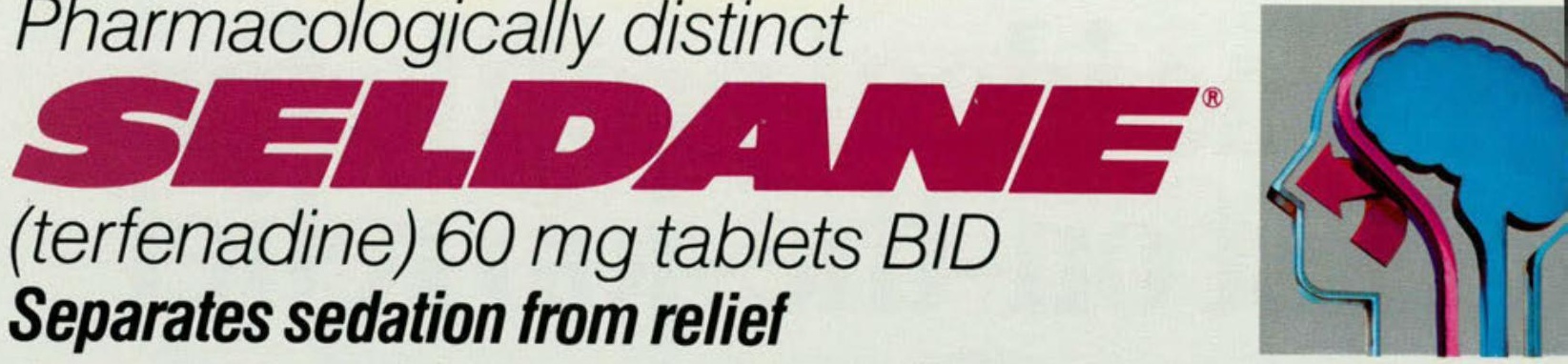

Patients with demanding jobs or busy schedules — at work, in school or at home — can't afford be drowsy. That's why Seldane, with its distinctive therapeutic profile plus its highly desirable pharmacokinetics, is the ideal choice for treating seasonal allergic rhinitis.

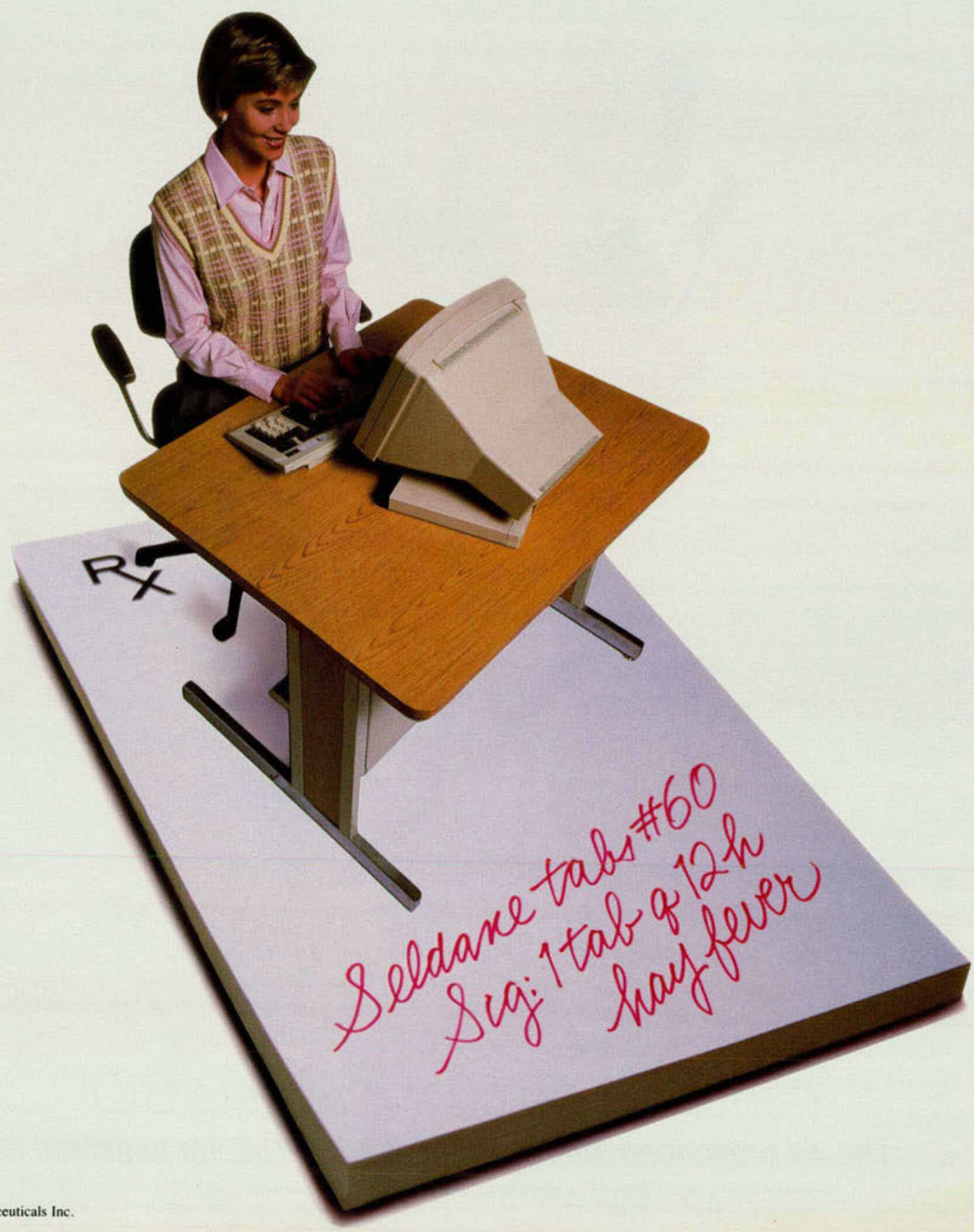




\section{For seasonal allergic rhinitis}

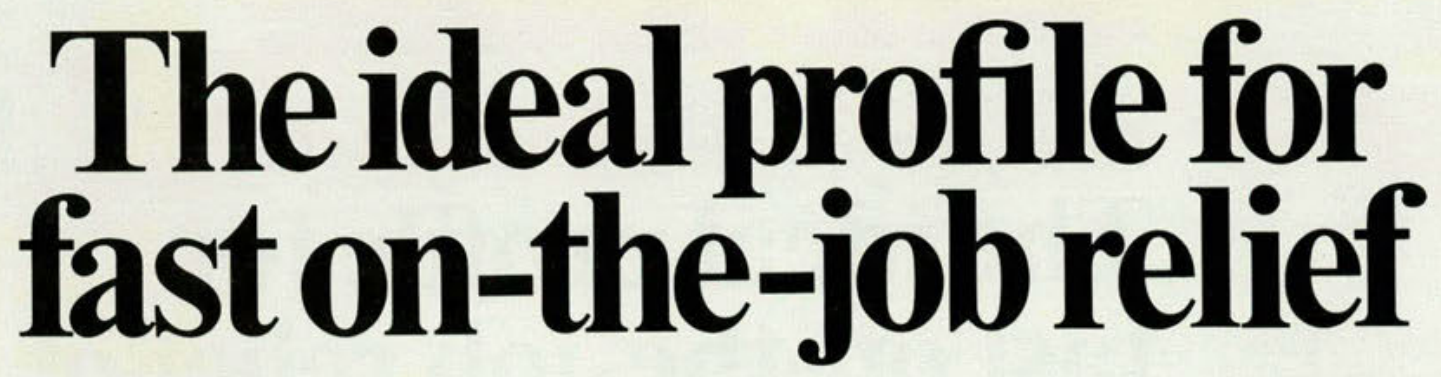

\section{Insurpassed antihistaminic potency}

Clinical studies around the world have proven Seldane ${ }^{\circledR}$ (terfenadine) as effective as assical antihistamines in relieving seasonal allergic rhinitis symptoms.'

\section{eparates sedation from relief ${ }^{* *}$}

Seldane was equivalent to placebo in drowsiness measured by multiple sleep latency sts, ${ }^{2}$ and did not differ significantly from placebo in reported incidence of drowsiness in ouble-blind studies involving more than 1,700 patients.'

\section{ow incidence of undesired effects}

Seldane was similar to placebo in the incidence of reported adverse effects in controlled udies.'

\section{Rapid onset of action}

Relief of symptoms within 1 hour after the first dose of Seldane was reported by most atients with hay fever. (Mean onset of action was 72 minutes.) ${ }^{3}$

\section{2-hour duration of action}

Antihistaminic action for 12 hours is provided by a $60 \mathrm{mg}$ tablet of Seldane, for convenient i.d. dosing outside working hours. ${ }^{1,4,5}$

\section{Short elimination time}

Within 24 to 48 hours after the last dose, the concentration of Seldane in the body falls elow pharmacological response levels. ${ }^{1}$ Repeat skin testing can be conducted without undue vaiting.

\section{Unrestricted administration time}

Seldane can be taken at any time of day convenient for the patient, twice daily.

\section{Extensive worldwide experience}

Seldane is now used in 33 countries and has amassed more than 26 million atient-months of experience worldwide. 


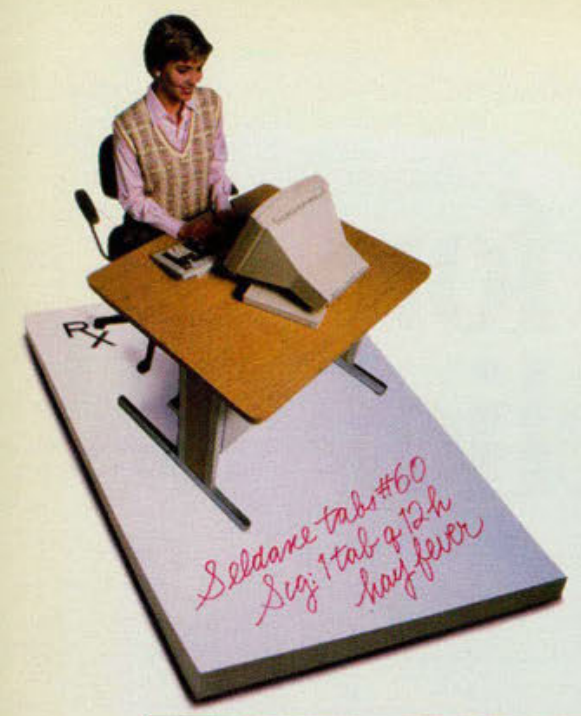

Pharmacologically distinct

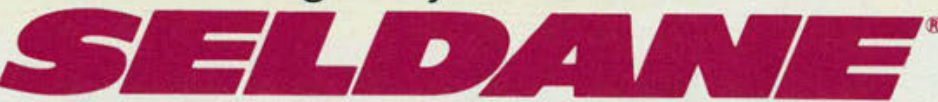

(terfenadine) $60 \mathrm{mg}$ tablets BID The \#1 prescribed allergy product in the U.S. The ideal profile for fast on-the-job relief of seasonal allergic rhinitis

\section{Seldane ${ }^{\circledR}$ (terfenadine)}

$60 \mathrm{mg}$ Tablets

CAUTION: Federal law prohibits dispensing without prescription.

DESCRIPTION

Seldane (terfenadine) is available as tablets for oral administration. Each tablet contains $60 \mathrm{mg}$ terfenadine. Tablets also contain, as inactive ingredients: corn starch, gelatin, lactose, magnesium stearate, and sodium bicarbonate.

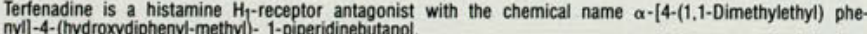
It has the following chemical structure:

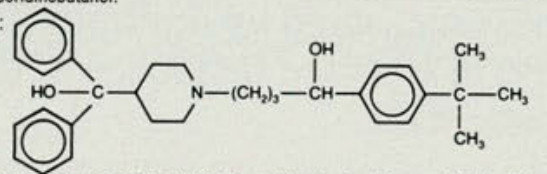

Terfenadine occurs as a white to off-white crystalline powder. It is freely soluble in chloroform, soluble in ethanol, and very slightly soluble in water.

\section{CLINICAL PHARMACOLOGY}

Terfenadine is chemically and pharmacologically distinct from other antihistamines.

Histamine skin wheal studies have shown that Seldane in single and repeated doses of $60 \mathrm{mg}$ in 64 subjects has an antihistaminic effect beginning at 1-2 hours, reaching its maximum at 3-4 hours, and lasting in excess of 12 hours. Clinical trials of Seldane involved about 2,600 patients, most receiving either Seldane, another antihistamine and/or placebo in double-blind, randomized controlled comparisons. The four best controlled and largest trials each lasted 7 days and involved about 1,000 total patients in comparisons of Seldane $(60 \mathrm{mg} \mathrm{b}$.i.d.) with an active drug (chlor-
pheniramine, $4 \mathrm{mg}$ t.i.d.; dexchlorpheniramine, $2 \mathrm{mg}$ t.i.d.; or clemastine $1 \mathrm{mg}$ b.i.d.). In the four trials, about pheniramine, $4 \mathrm{mg}$ t.i.d.; dexchlorpheniramine, $2 \mathrm{mg}$ t.i.d.; or clemastine $1 \mathrm{mg}$ b.i.d.). In the four trials, about $50-70 \%$ of Seldane or other antihistamine recipients had moderate to complete relief of symptoms, compared with
$30-50 \%$ of placebo recipients, with a significant difference favoring the active drugs in each study. In these studies, with Seldane was similar to the frequency with placebo. None of these studies showed a difference between Seldane and other antihistamines in the frequency of anticholinergic effects. In studies which included 52 subjects in whom EEG assessments were made, no depressant effects have been observed.

Animal studies have demonstrated that terfenadine is a peripheral specific histamine $\mathrm{H}_{1}$-receptor antagonist. In these animal studies, no sedative or anticholinergic effects were observed at effective antihistaminic doses. H.-receptors indicate that, at effective antihistamine doses, neither terfenadine nor its metabolites penetrate the blood brain barrier well.

Pharmacokinetic studies in 27 male subjects, using 14C-labeled terfenadine, demonstrated that an oral dose of terfenadine is well absorbed from the gastrointestinal tract and rapidly and extensively biotransformed. Following administration of a single $60 \mathrm{mg}$ Seldane tablet, detectable plasma levels were observed within one-half hour. Plasma levels peaked at about 2 hours after administration; a distribution half-life of 3.4 hours was followed by an elimination half-life of 20.25 hours. Terfenadine is extensively (97\%) bound to human serum protein. Elimination
studies in 6 male volunteers showed that fecal excretion accounted for $60 \%$ of the dose while $40 \%$ of the dose was eliminated via the urine. Almost all of the dose was eliminated in the form of metabolic products.

Following administration of single doses of 60 or $180 \mathrm{mg}$ of Seldane, a linear response was observed in maximum plasma concentration. Area under the curve (AUC) calculations, however, indicate a nearly four-fold increase in response for a three-fold increase in dose.

INDICATIONS AND USAGE Seldane is indicated for the relief of symptoms associated with seasonal allergic rhinitis such as sneezing.
minorrhea, pruritus, and lacrimation.

CONTRAINDICATIONS

Seldane is contraindicated in patients with a known hypersensitivity to terfenadine or any of its ingredients.

PRECAUTIONS

Information for patients

Patients taking Seldane should receive the following information and instructions. Antihistamines are prescribed to therapy, since the drug should be used in pregnancy or lactation only if the potential benefit justifies the Seldane risk to fetus or baby. Patients should be instructed to take Seldane only if the potential benefit justifies the potential dose. Patients should also be instructed to store this medication in a tightly closed container in a cool, dry place. away from heat or direct sunlight, and away from children.

Carcinogenesis, mutagenesis, impairment of fertility

Oral doses of terfenadine, corresponding to 63 times the recommended human daily dose, in mice for 18 months or in rats for 24 months, revealed no evidence of tumorigenicity. Microbial and micronucleus test assays with tertenadine have revealed no evidence of mutagenesis.

Reproduction and fertility studies in rats showed no effects on male or female fertility at oral doses of up to 21 times the human daily dose. At 63 times the human daily dose there was a small but significant reduction in implants and at 125 times the human daily dose reduced implants and increased post-implantation losses were observed, which were judged to be secondary to maternal toxicity.

Pregnancy Category $C$

There was no evidence of animal teratogenicity. Reproduction studies have been performed in rats at doses 63 times and 125 times the human daily dose and have revealed decreased pup weight gain and survival when terfenadine was administered throughout pregnancy and lactation. There are no adequate and well-controlled
studies in pregnant women. Seldane should be used during pregnancy only if the potential benefit justifies the potential risk to the fetus.

Nonteratogenic effects
Seldane is not recommended for nursing women. The drug has caused decreased pup weight gain and survival in rats given doses 63 times and 125 times the human daily dose throughout pregnancy and lactation. Effects on exposed to Seldane only during lactation are not known, and there are no adequate and well-controlled stud
women during lactation. women during lactation.

Pediatric use

Safety and effectiveness of Seldane in children below the age of 12 years have not been established. General

Consideration should be given to potential anticholinergic (drying) effects in patients with lower airway dise including asthma.

\section{ADVERSE REACTIONS}

Experience from clinical studies, including both controlled and uncontrolled studies involving more than 2 patients who received Seldane, provides intormation on adverse experience incidence for periods of a few day was as low as $20 \mathrm{mg}$ twice a day, or as high as $600 \mathrm{mg}$ daily. In controlled clinical studies using the recommended dose of $60 \mathrm{mg}$ b.i.d., the incidence of reported adv
effects in patients receiving Seldane was similar to that reported in patients reciving placebo. ADVERSE EVENTS REPORTED IN CLINICAL TRIALS

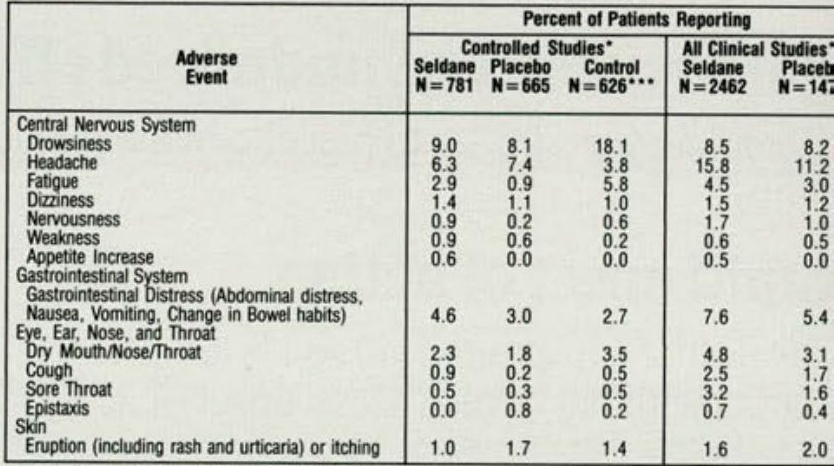

-Duration of treatment in "CONTROLLED STUDIES" was usually 7-14 DAYS.

*Duration of treatment in "ALL CLINICAL STUDIES" was up to 6 months.

-CONTROL DRUGS: Chlorpheniramine (291 patients), $d$-Chlor-pheniramine (189 patients), Clemastine

In addition to the more frequent side effects reported in clinical trials (See Table), adverse effects have reported at a lower incidence in clinical trials and/or spontaneously during marketing of Seldane that warrant lis as possibiy associated with drug administration. These include: alopecia, anaphylaxis, angioedema, arrhyth bronchospasm, confusion, depression, galactormea, insomnia, menstrual disorders (including dysmenorrh musculoskeletal symptoms, nightmares, palpitation, paresthesia, sweating, tachycardia, tremor, urinary quency, and visuar cisturbances. In clinical triass, severa instances of mild, or in one case, moderate transamir Marketing werperiences include isolated reports of iaundice cholestatic hepatitis, and hepatitis: in most vailable information is incomplete. In neither the clinical trials nor marketing experience is a causal relationsh liver abnormalities to Seldane use clear.

OVERDOSAGE

Several cases of overdosage have been reported. Generally, signs and symptoms were absent or mild (e

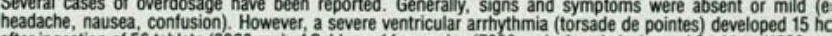
after ingestion of 56 tablets ( $3360 \mathrm{mg}$ ) of Seldane, 14 capsules $(7000 \mathrm{mg}$ ) of cephalexin, and 2 tablets (1200 mg buprofen. This progressed to ventricular fibrillation which responded well to defibrillation and lidocaine.

Therefore, in cases of overdosage, cardiac monitoring for at least 24 hours is recommended, along with stanc measures to remove any unabsorbed drug. It is not known if Seldane is dialyzable.

Treatment of the signs and symptoms of overdosage should be symptomatic and supportive after the acute stc Oral LDso values for terfenadine were greater than $5000 \mathrm{mg} / \mathrm{kg}$ in mature mice and rats. The oral LDso was $\mathrm{mg} / \mathrm{kg}$ in newborn rats. Single doses as high as ten times $(600 \mathrm{mg})$ the recommended therapeutic dose in ad have been wh

DOSAGE AND ADMINISTRATION

HOW SUPPLIED

$60 \mathrm{mg}$ tablets in bottles of 100 . Tablets are round, white, and debossed "SELDANE" Store tablet

controlled room temperature $\left(59^{\circ}-86^{\circ} \mathrm{F}\right)\left(15^{\circ}-30^{\circ} \mathrm{C}\right)$. Protect from exposure to temperatures above 10
$\left(40^{\circ} \mathrm{C}\right)$ and moisture. Product Information as of January, 1987 MERRELL DOW PHARMACEUTICALS INC. Subsidiary of The Dow Chemical Company

Merrell Dow

\section{References:}

1. Data available upon request, MERRELL DOW PHARMACEUTICALS INC., Cincinnati, Ohio 45215. 2. Roehrs TA, Tietz EI, Zorick FJ, et al: Daytime sleepiness and antihistamines. Sleep 7(2):137-141, 1984. 3. Murphy-O'Connor JC, Renton RL. Westlake DM: A double-blind comparative trial of two dose regimens of terfenadine in patients with hay fever. J Int Med Res 12:333-337, 1984 4. Hūther KJ, Renftle G, Barraud N, et al: Inhibitory activity of terfenadine in histamine-induced skin wheals in man. Eur J Clin Pharmacol 12:195-199, 1977. 5. Reinberg A, Levi F, Guillet P, et al: Chronopharmacological study of antihistamines in man with special references to terfenadine. Eur J Clin Pharmacol 14:245-252, 1978.

7-0119U (SE034B) MDA017C MNQ374 